\title{
The Workshop in the Multilayered Peer Coaching Model for Tertiary EFL Teachers' In-Service Professional Development
}

\author{
Junyi Meng $^{1} \&$ Songphorn Tajaroensuk ${ }^{1}$ \\ ${ }^{1}$ School of Foreign Languages, Institute of Social Technology, Suranaree University of Technology, Thailand \\ Correspondence: Junyi Meng, Room 3015, Surasammanakhan Hotel, Suranaree University of Technology, 111 \\ University Avenue, Muang District, Nakhon Ratchasima 30000, Thailand. Tel: 86-138-0943-8270. E-mail: \\ jymeng66@hotmail.com
}

$\begin{array}{ll}\text { Received: May 15, } 2013 & \text { Accepted: June 3, } 2013 \quad \text { Online Published: July 4, } 2013 \\ \text { doi:10.5539/elt.v6n8p44 } & \text { URL: http://dx.doi.org/10.5539/elt.v6n8p44 }\end{array}$

\begin{abstract}
When English becomes the international language with the globalization of the world, it is not surprising that EFL teachers are pushed to the front of TEFL (Teaching English as a Foreign Language) because teacher quality is thought to be the factor that matters most for student learning. EFL teachers are expected to be more knowledgeable and competent. So their in-service professional development seems to be indispensable to help them reach higher professionalism. This study aimed at investigating the activities and effectiveness of the workshop that is an important element of the Multilayered Peer Coaching Model (the MPC Model) developed for tertiary EFL teachers' in-service professional development. Twelve EFL teachers from Guiyang University in China participated in this study, and such instruments as observation, teachers' log and interview were employed for data collection. The results showed that this workshop was effective and could smoothly lead the participants to the follow-up teaching practice which is another critical element of the MPC Model.
\end{abstract}

Keywords: in-service professional development, tertiary EFL teachers, the Multilayered Peer Coaching Model, workshop

\section{Introduction}

The global spread of English has affected all the domains of human activity from language in education to international relationship (Kachru, 2011). The situation that "400 million people speak English as their first language and 750 million people speak English as their second language" (Herther, 2009) has expected better quality of the English instruction. Apart from it, the increasing number of people learning English as a foreign language has upgraded the professionalism of Teaching English as a Foreign Language (TEFL). DarlingHammond (1998) once argued that teacher quality is the factor that matters most for student learning. Therefore, EFL teachers are confronted with the challenge from their profession. TEFL in China is also in its reform for keeping pace with the requirements of the rapid economic development of China. New standards and regulations have been updated or issued for English language learning and teaching at the tertiary level, for example, the "Syllabus for English Majors of Colleges or Universities" (revised in 2001) and the new "College English Curriculum Requirement" (issued in 2006). For such higher professionalism, EFL teachers working at colleges or universities are greatly encouraged to have their in-service professional development.

However, it is not easy for tertiary EFL teachers to have their in-service professional development. Many factors have been found to be the contributors, and one of them is their heavy workload. The tertiary EFL teachers in China can be a case in point. Generally speaking, tertiary EFL teachers in China are generally put into two sectors: one is for non-English majors and the other is for English majors. The former sector teaches general English skills, exactly, listening, speaking, reading, writing, and translating; the latter sector teaches both general English and specialized courses such as English linguistics, American and British literature, translation between Chinese and English, culture studies, English teaching methodology, etc. Since the year of 1998, China has increased its college enrollment, during the 1996-2000 period there was a total enrollment of over 11 million, from 2001 to 2005 the number of university students would be up to 16 million (CERNET, 2001), so the workload for both sectors has increasingly been heavier. Likewise, another factor hindering the EFL teachers' in-service professional development is the lack of effective programs. Tsui (2003) once claimed that EFL profession is facing two problems, the lack of teacher training programs and the dissatisfaction with 
conventional training models. Ono and Ferreira (2010) have also affirmed that many models of professional development do not achieve their ambitious learning goals.

Based on these factors and the needs analysis of the tertiary EFL teachers who participated in the experiment conducted by the researcher of this present study, the Multilayered Peer Coaching Model (the MPC Model) was developed for tertiary EFL teachers' in-service professional development. (Note 1) A workshop was designed as an important element of the MPC Model.

As it is defined, a workshop is an intensive, short-term learning activity that is designed to provide an opportunity to obtain the specific knowledge and skill (Richards \& Farrell, 2005). It is one of the most common and useful forms of professional development activities for teachers (Richards, Gallo, \& Ranendya, 2001). However, not every teacher has experienced effective workshops during their careers, many of them find the workshops they attended are less effective (Dickey, 2008). Workshops have even been criticized as being brief, fragmented, incoherent encounters that are decontextualised and isolated from real classroom situations (e.g. Fullan \& Hargreaves, 1996; Collinson \& Ono, 2001; Schwille \& Dembélé, 2007). As a matter of fact, the hit-or-miss of a workshop depends on a great deal of preliminary thought or planning, and as the name implies, it is a place where work is accomplished, directed to the collaborative exploration and resolution of problems (Richards \& Farrell, 2005).

Therefore, this study aimed at investigating the effectiveness of this workshop that is an important element of the MPC Model, and identifying the activities of this workshop for tertiary EFL teachers' in-service professional development. This study provided the answers to the following research questions:

1. What activities are conducted in the workshop of the MPC Model?

2. Does the workshop of the MPC Model help to train the tertiary EFL teachers to update their professional knowledge and skills? If yes, to what extent? If not, why not?

\section{The Multilayered Peer Coaching Model}

The Multilayered Peer Coaching Model (the MPC Model) was developed for tertiary EFL teachers' in-service professional development. It can be defined as "the practice of peer coaching within a team teaching context in the TEFL setting which can offer teachers more opportunities to support one another in their work." In this practice, teachers may experience two layers of collaboration. The first layer is team teaching in which four teachers can be involved as a team so that common issues and problems will be discussed and solved by pooling the ideas of the team members. The second layer is peer coaching where two dyads will be formed within the team so that the two peer teachers in each dyad will work together to reflect on current practices, expand, refine, and build new skills, share ideas; teach each other; conduct classroom research; or solve problems in the workplace.

The MPC Model was developed on the basis of the ADDIE Model, which is one of the most popular instructional system design (ISD) theories and has withstood the test of time and use. The acronym "ADDIE" stands for Analysis, Design, Development, Implementation, and Evaluation, which represents an arrangement of resources and procedures used to promote learning (Gagné \& Wager, 1988) or a dynamic, flexible guideline for building effective training and performance support tools (See Figure 1).

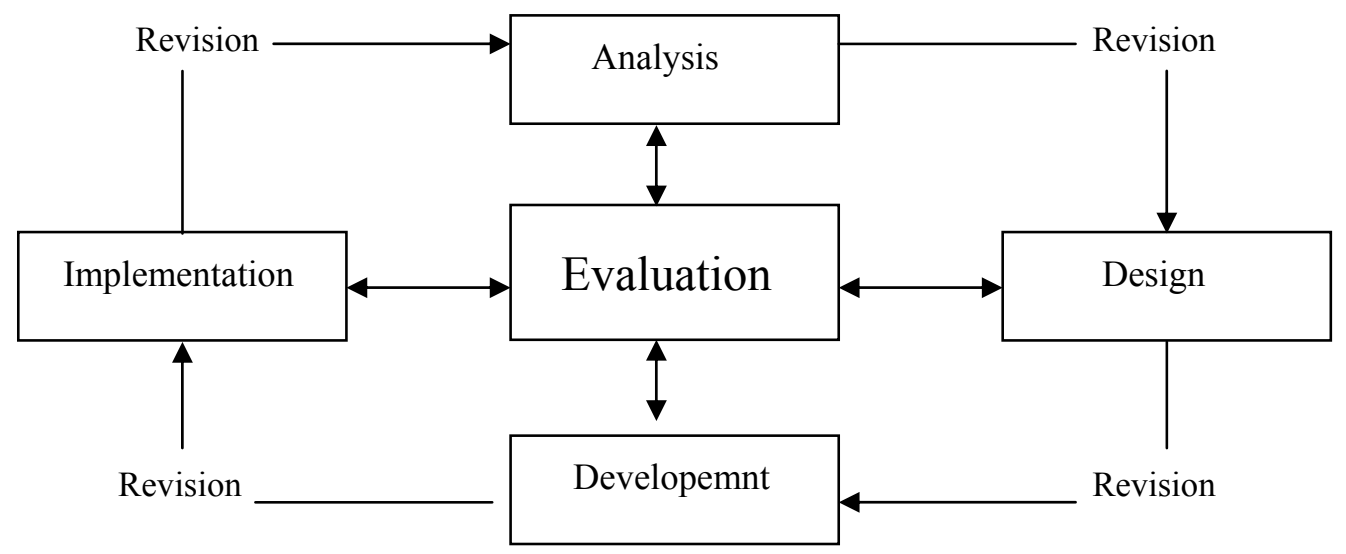

Figure 1. The ADDIE Model (Source: http://en.wikipedia.org/wiki/ADDIE_Model) 
The MPC Model had its conceptual framework which intended to display the operationalization of the ISD theory the MPC Model followed in its development. In order to show the relationship between each phase of the MPC Model and that of ADDIE, the figure "the ADDIE correspondence with the MPC Model" was made. The bottom part of this figure was the ADDIE's phases, and the rest part was the MPC Model's conceptual framework. The dotted lines showed the match between the phases of these two models. The detail was presented in Figure 2 as follows:

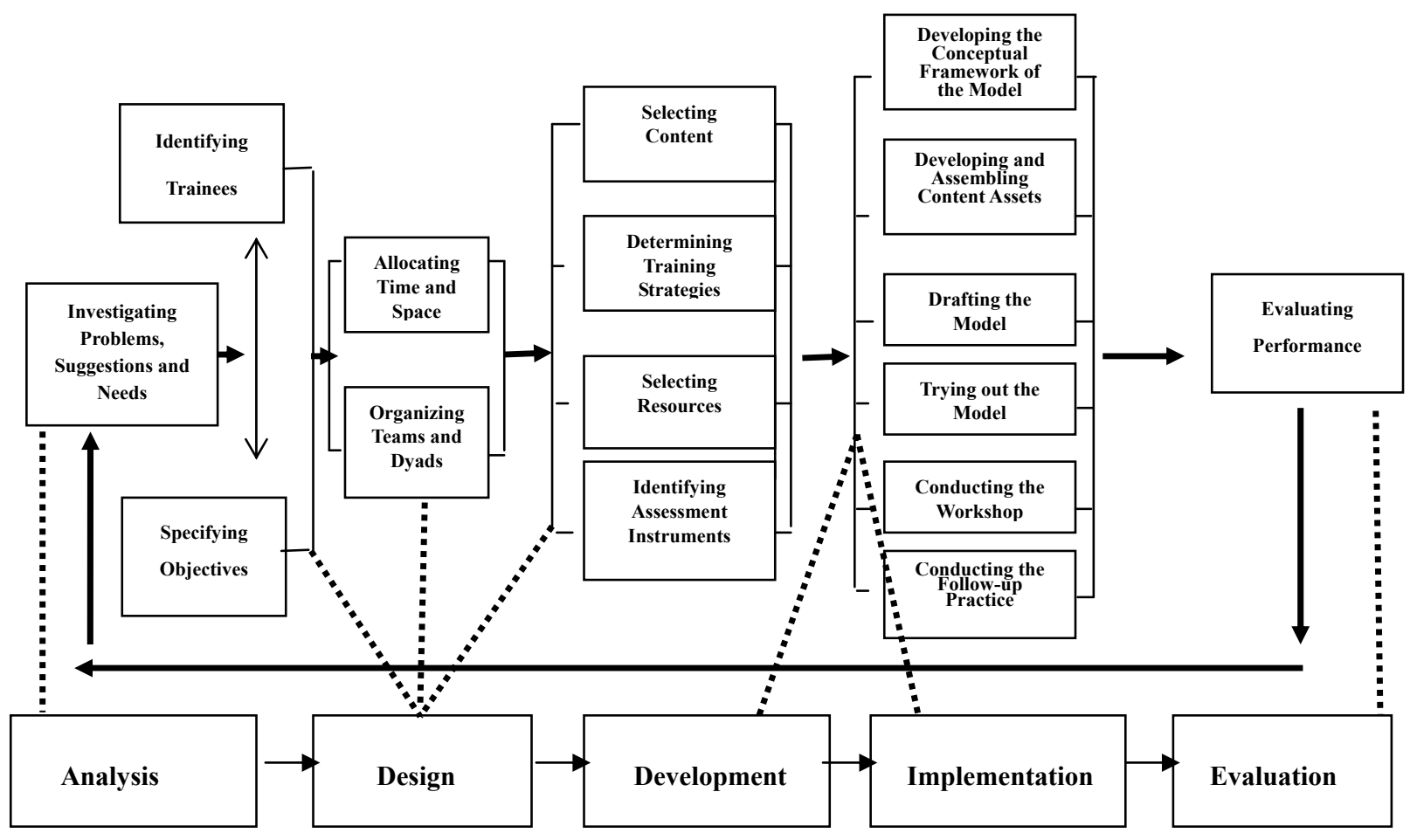

Figure 2. The ADDIE Correspondence of the MPC Model

In addition, the MPC Model also had its research procedure including five phases (See Figure 3) and 15 steps. Each of the five phases with its own elements displayed the detailed process for developing the MPC Model.

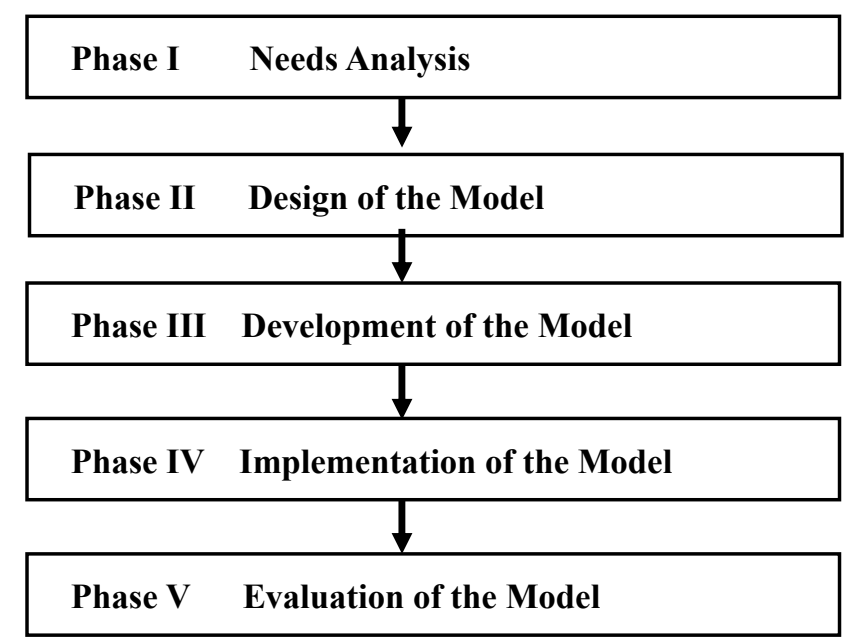

Figure 3. The Process of Developing the MPC Model 
"Phase I: Needs Analysis" was for the tertiary EFL teachers' problems and suggestions on their in-service professional development, and their needs for the MPC Model. "Phase II: Design of the model" was a systematic and specific phase, in which trainees, training objectives, environment, content, methods, and assessment instruments were identified. "Phase III: Development of the model" was a critical phase, in which such steps were followed: a) the conceptual framework was developed; b) the content of instruction was developed; c) the content of the training lessons was evaluated by the experts in the field of TEFL; 4) the MPC Model was drafted; 5) the MPC Model was tried out; 6) the model was finalized. The in-service tertiary EFL teachers' feedback and suggestions were considered.

It terms of "Phase IV: Implementation of the model", it is a practical phase, in which the experiment was conducted, and the workshop is one of the important elements (See Figure 4 below for the details of this phase). First, on the day before the experiment, the 12 teacher participants were pre-tested on their knowledge of both TEFL and the required teaching materials. Second, the teachers were grouped into three teams with two dyads in each based on their teaching duration. Third, the teachers received the training in the 3-day workshop by an external expert and the researcher. The training started with the expert's lecture on the new concept and updated knowledge of TEFL, and then the MPC Model was introduced by the researcher, after that, the teachers practiced the collaborative approach they had just learned. As soon as the workshop was over, the teachers moved on to the follow-up teaching by practicing the multilayered peer coaching in the intact classes for 15 weeks. Fourth, after each lesson, the teachers wrote the teacher's logs to show their procedure and feedback. Meanwhile, the researcher observed the teachers' classroom teaching and cooperation, and kept her field notes after each lesson. Fifth, after the experiment, a post-test was given to the teachers. Sixth, the questionnaires were conducted to find out the students' opinions on the instruction given by the teachers involved in the MPC Model and the teachers' opinions on the MPC Model. Finally, the interview was adopted to obtain the in-depth information about the teachers' attitudes towards the MPC Model.

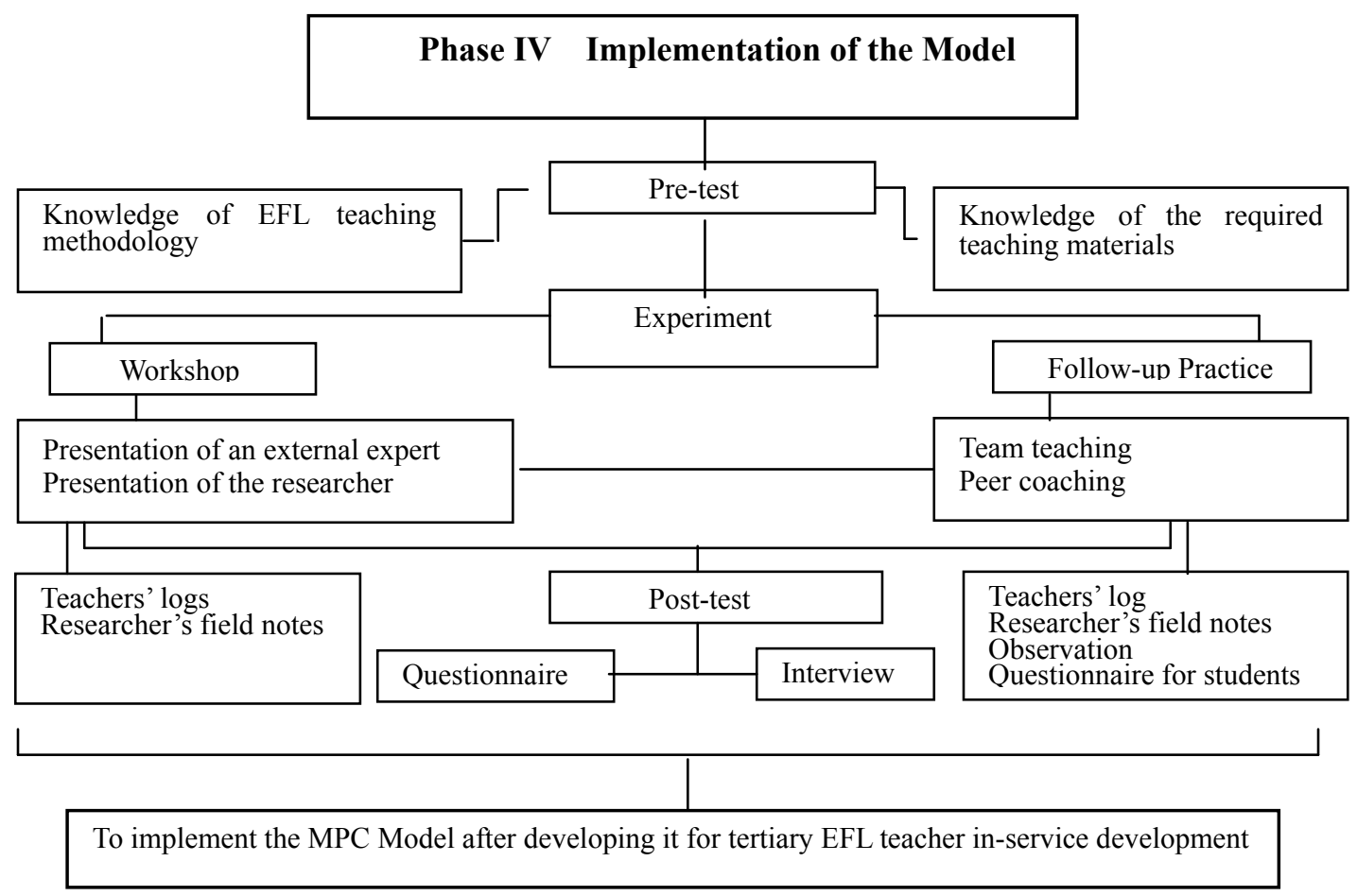

Figure 4. The Research Procedure in Phase IV of the MPC Model

Phase V: Evaluation of the model was an indispensable phase, in which the Model's effectiveness and the teachers' performance were measured. Actually, the evaluation was conducted throughout the entire instruction design process, whether within phases, or between phases, or after the implementation.

To conclude, the MPC Model served as an effective training support tool for tertiary EFL teachers' in-service professional development. With the multilayered peer coaching practice, the teachers could have and sustain their professional development in their daily teaching, which contributed a lot to the continuity of their in-service 
professional development.

\section{The Workshop of the Multilayered Peer Coaching Model}

In the implementation phase of the MPC Model, a 3-day workshop was designed for the beginning of the experiment. The teachers received the training in this workshop with the help of an external expert and the researcher of this present study. The workshop offered the teacher updated professional knowledge and skills, which would be further reinforced in the follow-up teaching practice with the intact classes for 15 weeks. The details of this workshop were as follows:

\subsection{Workshop Rationale}

This workshop provided a framework for organizing a tertiary EFL teachers' training program via the MPC Model, with a focus on its contribution to tertiary EFL teachers' in-service professional development. The drivers of this workshop included the following aspects:

a) the higher level of professionalism in TEFL today than previously;

b) the release of the new curriculum requirements by China's Ministry of Education;

c) the situation in Chinese universities whose EFL teachers can not sustain their professional development;

d) recognition that in-service professional development can help EFL teachers to meet the expectation of this profession;

e) recognition that there is the gap in a review of the academic literature on in-service professional development for tertiary EFL teachers, especially on peer coaching or team teaching.

\subsection{Workshop Objectives}

This workshop focused on the principle that the best way to improve teachers' in-service professional development was by their active involvement in the cooperation with colleagues, and their contributions to the teamwork mattered. So the objectives of this workshop were

a) to provide EFL teachers with an opportunity to learn new knowledge and skills via the MPC Model;

b) to facilitate EFL teachers to update their professional knowledge and competence by cooperating with their colleagues;

c) to present a concentrated but integrated discussion of effective innovations in English curriculum and delivery of instruction to support program implementation.

For such objectives, this meant giving teachers ample time and space to stay together to plan, teach and reflect on what they were doing for the course, and giving evidence that they were growing and changing as an EFL teacher in their professional knowledge and competence.

\subsection{Workshop Approaches}

In terms of the approaches or methods, this workshop was process-oriented, so group work, pair work, oral presentation, self-reflection, and lecture were applied in this workshop. All the methods took the following four parts as the guidance for the activities of the participants.

\section{a) Problem Discussion}

They discussed the problems existing in the their EFL teaching, and the problems existing in their professional development, and then their related suggestions, which led to further discussion on the updated English language competence and TEFL methodology in practice.

b) Direct Instruction Presentation

They were involved in the lectures given by the expert, and practiced what they had learned later in this workshop. Meanwhile, the participants themselves also presented their mini lessons in this workshop.

c) Cooperative Practice

They practiced the mini EFL lessons in group work, in peer coaching where a dyad worked together, and in team teaching where all the dyads worked together, and then gave their reflections on what they had done, which inductively helped to draw their ideas of cooperative teaching, to have a better understanding of the definitions and natures of peer coaching and team teaching.

d) Multilayered Peer Coaching Practice

They implemented the MPC Model in this workshop, and their reflections contributed to the measurement of this 
model. Then they got to know the model by keeping practicing it and gradually had their conceptualization of this model.

\subsection{Workshop Participants and Length}

Twelve tertiary EFL teachers, one expert in the field of TEFL, and the researcher of this present study participated in this workshop. It was conducted for three days, with 8 hours or 4 sessions per day.

\subsection{Workshop Expected Outcomes}

This workshop structure attempted to model the practice in multilayered peer coaching by having expected outcomes as follows. Each participant would

a) get a better understanding of the importance of cooperative teaching and its contribution to in-service professional development;

b) learn how to effectively lead his or her peer within their own professional abilities and personality styles;

c) learn how to effectively collaborate under the same tasks by making his or her own contribution;

d) learn more on how to effectively solve problems and respectfully work out issues with the help of their peers and team members;

e) learn how to create more effective working relationships;

f) learn how to be more service oriented.

\subsection{Workshop Session}

This workshop lasted three days with eight hours per day. Four 2-hour sessions are arranged in the morning and afternoon respectively each day with coffee/tea break and lunch in between. So there are twelve sessions in this workshop in total. In each session, the training had its specific topic and practice, with the cooperation of the teacher participants in dyads and teams.

To conclude, this workshop, which served as an important part of the MPC Model, helped to train the teachers with new knowledge and skills of TEFL. Meanwhile, it also offered the platform to them for cooperating with each other so that they know how to work together for their in-service professional development.

\section{Research Methodology}

\subsection{Participants}

Twelve tertiary EFL teachers from the School of Foreign Languages at Guiyang University in China participated in this study. They teach the "Comprehensive English Course". They were grouped into 6 dyads in 3 teams, with 2 dyads in a team according to their teaching duration. The participants were selected on the basis of purposiveness and availability.

\subsection{Instruments}

Three instruments were employed for data collection, namely, non-participant observation, teacher's log and semi-structured interview. The observation checklist was designed, or exactly, modified on the Waston's activities (Waston et al, 1998, cited in Richards \& Farrell, 2005) to find out the activities that this workshop offered and those the teacher participants conducted in this workshop; the teacher's log was used for the teacher participants to record their learning, teaching and cooperation, and to keep their reflection as well; a semi-structured interview was employed to find more in-depth information about the teacher participants' opinions on the workshop of the MPC Model. Some related questions were offered, which were checked by the experts for validity and reliability.

\subsection{Data Collection and Data Analysis}

While collecting the data, the workshop was video recorded, and the researcher filled out the observation checklists based on both on-the-spot observation and video-recordings. The teacher participants were asked to fill in the teacher's logs to record their training, in which the content of the lecture, the team discussion, the procedure of their peer coaching, especially the application of the new strategies by the peer teachers of each dyad before, during, and after the mini lessons, and the log also offered the space to have the teachers' reflection on this workshop. Besides, the 12 teacher participants were interviewed at the end of this workshop, the questions consisted of the teacher participants' opinions on this workshop.

While analyzing the data, frequency and content analysis were employed. The data from the checklists were analyzed by the frequency for the occurrence of the activities. The data from the teacher's logs and interview 
were analyzed by content analysis. For the data from the teacher's logs, they were already the written texts and then could be directly progressed according to the steps of content analysis; for the data from the interview, the audio-taped data were firstly transcribed, and then the transcribed data followed the other steps of content analysis.

\section{Results}

After the data were analyzed, the researcher tried to relate the results to the research questions in this study. The responses to the two research questions were presented respectively based on the instruments.

\subsection{Results of Research Question One}

\subsubsection{Data from the Observation}

Table 1. The Results of Observation Checklist for the Workshop's Activities

\begin{tabular}{lccccc}
\multicolumn{1}{c}{ Observation Items } & \multicolumn{3}{c}{ Sessions } & & \\
& Day $\mathbf{1}$ & Day 2 & Day 3 & M & SD \\
\hline 1. Direct Instruction Presentation & 2 & 1 & 0 & 1.00 & 1.00 \\
2. Trainee's Presentation & 2 & 4 & 4 & 3.33 & 1.15 \\
3. Discussion & 4 & 4 & 4 & 4.00 & 0.00 \\
4. Partner Work & 4 & 4 & 4 & 4.00 & 0.00 \\
5. Co-planning Activities & 4 & 4 & 4 & 4.00 & 0.00 \\
6. Role-play/ Practice & 4 & 4 & 4 & 4.00 & 0.00 \\
7. Reflection & 4 & 4 & 4 & 4.00 & 0.00 \\
\hline
\end{tabular}

As shown in Table 1, this workshop offered 7 activities during the 12 sessions in 3 days, on average, 4 sessions a day. The seven activities were conducted in different frequencies. For example, item No. 3, 4, 5, 6, and 7 were most conducted with the mean score of 4.00 and the standard deviation of 0.00 , which explained that the activities of Discussion, Partner Work, Co-planning, Role-play, and Reflection took place in each session. Item No. 1 was conducted the least (the mean score of 1.00 and the standard deviation of 1.00), which meant that the trainer's Direct Instruction Presentation was quite limited, and item No. 2 had its the mean score of 3.33 and the standard deviation of 1.15 showed that the trainee's Presentation was conducted more and more especially on the last two days. This implied this workshop was very practice-based and focused on the cooperation of the participants.

Table 2. The Results of Observation Checklist for the Teachers' Activities in the Workshop

\begin{tabular}{|c|c|c|c|c|c|c|c|c|}
\hline Teacher & $\begin{array}{c}\text { Lecture } \\
\text { Attendance }\end{array}$ & Q\&A & Discussion & $\begin{array}{l}\text { Observation } \\
\text { Presentation }\end{array}$ & $\begin{array}{l}\text { Items } \\
\text { Peer } \\
\text { Work }\end{array}$ & Co-planning & $\begin{array}{l}\text { Role-play/ } \\
\text { Practice }\end{array}$ & Reflection \\
\hline T1 & 3 & 12 & 12 & 10 & 12 & 12 & 12 & 12 \\
\hline $\mathrm{T} 2$ & 3 & 12 & 12 & 9 & 12 & 12 & 12 & 12 \\
\hline $\mathrm{T} 3$ & 3 & 11 & 12 & 10 & 12 & 12 & 12 & 12 \\
\hline $\mathrm{T} 4$ & 3 & 12 & 12 & 10 & 12 & 12 & 12 & 12 \\
\hline T5 & 3 & 12 & 12 & 10 & 12 & 12 & 12 & 12 \\
\hline T6 & 3 & 12 & 12 & 9 & 12 & 12 & 12 & 12 \\
\hline $\mathrm{T} 7$ & 3 & 12 & 12 & 10 & 12 & 12 & 12 & 12 \\
\hline $\mathrm{T} 8$ & 3 & 10 & 12 & 10 & 12 & 12 & 12 & 12 \\
\hline Т9 & 3 & 12 & 12 & 8 & 12 & 12 & 12 & 12 \\
\hline $\mathrm{T} 10$ & 3 & 12 & 12 & 10 & 12 & 12 & 12 & 12 \\
\hline $\mathrm{T} 11$ & 3 & 12 & 12 & 10 & 12 & 12 & 12 & 12 \\
\hline $\mathrm{T} 12$ & 3 & 12 & 12 & 8 & 12 & 12 & 12 & 12 \\
\hline Mean & 3.00 & 11.90 & 12.00 & 9.50 & 12.00 & 12.00 & 12.00 & 12.00 \\
\hline SD & 0.00 & 0.28 & 0.00 & 0.79 & 0.00 & 0.00 & 0.00 & 0.00 \\
\hline
\end{tabular}


Table 2 showed that the teacher participants went through the workshop with the help of the activities that they conducted. The activities that were done in each session included Discussion, Peer Work, Co-planning, Role-play, and Reflections with the mean scores of 12.00 and the standard deviation of 0.00 . The activity of Questions \& Answers was also conducted very frequently with the mean score of 11.90 and the standard deviation of 0.28 . Meanwhile, the teacher participants' presentation was made in most cases of this workshop, which had the mean score of 9.50 and the standard deviation of 0.79 . Likewise, they attended the lectures offered in this workshop three times in total with the mean score of 3.00 and the standard deviation of 0.00 . The results indicated that the teacher participants conducted the activities in high frequency. Because of being rooted in the cooperation within a dyad and a team and putting emphasis on the practice, these activities contributed to their good command of professional knowledge and skills.

\subsection{Results of Research Question Two}

\subsubsection{Data from the Teacher's Log}

The results from the teacher's logs showed that the teacher participants kept their logs about the steps they followed, the activities they conducted, the cooperation they made during this workshop, and their refection on them. The results were presented based on two themes: activity and reflection.

For their activities, the logs showed that, first, they attended the trainer's lectures in the first, third and fifth session about some EFL teaching theories or principles, such as Task-Based Language Teaching (TBLT), Communicative Language Teaching (CLT), and then they applied what they learned to the practice; second, they were grouped into the team and dyad. With their team members and peer teacher, they began to make the cooperation according to the directions; third, they did the group discussions on the pro and con of TBLT, CLT, etc. and how to select the teaching materials was also a focus in their discussion; fourth, they did team co-planning and peer work for their mini lessons from preparation to presentation. For their reflections, they thought that: a) this workshop was very interesting and helpful. Fewer lectures and more practice made them feel less bored, and they could use what they learned immediately, which helped to keep them in mind; b) this workshop was more supportive by implementing the MPC Model. They felt stronger and more confident by working with both peer teachers and team members; c) this workshop offered them the chance to know their colleagues better. They enjoyed working with friends, as they said "more heads are better than one". Therefore, the results implied that this workshop trained the teacher participants with updated professional knowledge and skills for their in-service professional development.

\subsubsection{Data from the Interview}

The results from the interview presented their positive opinions on this workshop. To the questions they were asked, all of the 12 teachers gave their responses. 1) Regarding their general feeling on this workshop, they said they seemed to be very excited about their work all the time in this 3-day workshop. Although they attended some workshops before, it was the first time to have such a feeling. 2) In terms of their updated professional knowledge and skills, they said they had more exposure to the new information in the workshop. They learned new TEFL knowledge and skills, and practiced them immediately in peers and teams. The peer teachers' idea sometimes helped them reconsider their own plan or design, which led them back to the theories to find the support to convince the others. 3) About the lectures, they said that the lectures they attended in this workshop were wonderful because the content was what they needed. (The researcher developed the teaching contents based on their needs in her preliminary study). 4) As for their cooperation, they said they learned how to work with the colleagues in this workshop. They thought each of them had some specific skill in classroom teaching and research, working with others meant to a kind of study. 5) When asked if they liked the MPC Model at this level, they said they liked this model because it not only provided the cooperation in the dyads and teams, but also offered a follow-up teaching practice session after the workshop, in which they could reinforce and sustain their profession development. As one of them said, "This workshop refreshed my understanding of the workshop. To tell you the truth, I do not know what a workshop really is although I attended it many times. I don't know the difference between the workshop and other academic meeting, until I came to this workshop. It is really a 'workshop' because I practiced how to teach with team members, just like an apprentice. I know the workshop refers not only to what it is, but also how to do it." Therefore, the results revealed that the workshop helped to train the teacher participants with what they wanted for updating their professional knowledge and skills in their in-service professional development.

\section{Discussion}

According to the results presented above, this workshop's contribution to tertiary EFL teachers' in-service professional development and the teachers' attitudes towards this workshop were discussed as follows. 


\subsection{Contributions of this Workshop's Activities to Tertiary EFL Teachers' In-service Professional Development}

Based on the results of this study, the activities that this workshop planned were conducted by the teacher participants in a high frequency. Meanwhile, the teachers had their reflections which showed their satisfaction with these activities for their in-service professional development. This happened because all the activities were designed on a basis of the characteristics that a workshop should have for teacher training, and played the proper roles in teachers' professional development. These results were in consistent with some other studies. Richards and Farrell (2005) have stated that in a workshop the participants are expected to learn something that they can later apply in the classroom and get the hands-on experience with the topic. Usha Rani (2012) claimed that applied linguists cite eleven different approaches that promote professional development, and workshop is one of them and is listed as top one. Hands-on workshops typically involve the participants doing work on a particular issue during the program. The promise is that when they leave, they will have at least a rough plan or tools in place to address the challenge. Therefore, this implied that the workshop of the MPC Model could help the EFL teachers have their in-service professional development.

\subsection{Factors Leading to the Satisfaction of the EFL teachers with the Workshop of the MPC Model}

From the results of this study, the teachers thought that this workshop was very supportive and they felt stronger and more confident by working with peer teachers and team members. This happened because this workshop was rooted in the MPC Model which intended to put the practice of peer coaching within a team teaching context so as to offer teachers more opportunities to support one another in their work. Some other researchers have found the similar results in their studies. Darling-Hammond and Richardson (2009) reviewed 20 years of research on effective teacher learning and professional development, examining the content, context, and design of high quality professional development. They concluded that teachers learn most effectively and easily when learning is collaborative and collegial, and professional development is intensive and sustained over time. Colbert et al (2008) pointed out that when teachers collaborate, research indicates an increase in their academic content knowledge, and an increasing number of studies identify the importance of collaboration as a key characteristic of effective professional development.

The teachers also thought that this workshop offered them the chance to know their colleagues better, and to know how to work with each other. They enjoyed working with friends for their in-service professional development. This happened because the MPC Model equipped its workshop with a cooperative platform in which the teachers in the same schools or university spent lots of time working together for what they learned and their application to the mini lessons. Friendship made in their cooperation could encourage their learning interest. This was just consistent with some previous studies. Colbert et al (2008) claimed that collaboration should include groups within the same school or department so that teachers can work together in a focused environment while dealing with issues of common interest. Dove and Honigsfeld (2010) pointed out that when teachers engage in collaborative practices, they experience a reduction in isolation, enjoy more occasions to share their expertise, and appreciate the opportunity to shape the way the ESL program operates in their schools. This implied that the teachers in such a context were willing to have their in-service professional development.

\section{Conclusion}

This study has been conducted to investigate the effectiveness of the workshop in the MPC Model, and identify the activities that this workshop offered for tertiary EFL teachers' in-service professional development. The results from this study have contributed to the field of research on EFL teachers' professional development. It was found that the workshop in the MPC Model could help the teachers obtain the hands-on experiences effectively and then help them move on to the follow-up teaching practice in the real teaching context smoothly. The teachers had positive opinions on the workshop of the MPC Model because they had their professional knowledge and competence updated with effect in it. So they were willing to apply this workshop for their in-service professional development. Furthermore, further research can be conducted to help tertiary EFL teachers focus on the follow-up teaching practiced after the workshop so that their in-service professional development will be sustained via the MPC Model.

\section{Acknowledgements}

The authors wish to thank the experts who helped to evaluate the MPC Model and the instruments. They also want to thank the EFL teachers from Guiyang University in China, who were the main participants of this study.

\section{References}

CERNET. (2001). Chinese universities enroll 2.6 million freshmen. Education in China. Retrieved February 2, 2013, from http://www.edu.cn/200108_1470/20060323/t20060323_5346.shtml 
Colbert, J. A., Brown, R. S., Choi, H. S., \& Thomas, S. (2008). An investigation of the impacts of teacher-driven professional development on pedagogy and student learning. Teacher Education Quarterly, Spring, 135-154.

Collinson, V., \& Ono, Y. (2001). Professional development of teachers in United States and Japan. European Journal of Teacher Education, 24, 223-248. http://dx.doi.org/10.1080/02619760120095615

Darling-Hammond, L., \& Richardson, N. (2009). Teacher learning: What matters? Educational Leadership, 66(5), 46-53.

Darling-Hammond, L., \& Berry, B. (1998). Investing in teaching, Education Week. Retrieved May 27, 2012, from http://www.edweek.org/ew/vol17/37darlin.h17

Dickey, R. J. (2006). Review on professional development for language teachers: Strategies for teacher learning - Jack C. Richards and Thomas S. C. Farrell. Korea TESOL Journal, 8(1), 99-102. Retrieved 12 May, 2013, from http://www.koreatesol.org/content/korea-tesol-journal-8

Dove, M., \& Honigsfeld, A. (2010). ESL coteaching and collaboration: Opportunities to develop teacher leadership and enhance student learning. TESOL Journal, 1(1), 3-22. http://dx.doi.org/10.5054/tj.2010.214879

Fullan, M., \& Hargreaves, A. (1996). What's worth fighting for in your school. New York: Teachers College Press.

Gagné, R. M., Briggs, L. J., \& Wager, W. W. (1988). Principle of instructional design. Fort Worth: Holt, Rinehart, and Winston.

Herther, N. K. (2009). The changing language of search. Searcher: The Magazine for Database Professionals, February, 40-50.

Kachru, Y. (2011). World Englishes: Contexts and relevance for language education. In E. Hinkel (Eds.), Handbook of research in second language teaching and learning (pp. 155-172), New York: Routledge.

Ono, Y., \& Ferreira, J. (2010). A case study of continuing teacher professional development through lesson study in South Africa. South African Journal of Education, 30, 59-74.

Richards, J. C., \& Farrell, T. S. C. (2005). Professional development for language teachers. New York: Cambridge University Press.

Richards, J. C., Gallo, P. B., \& Renandya, W. A. (2001). Exploring teachers' beliefs and the processes of change. PAC Journal, 1, 41-58.

Schwille, J., \& Dembélé, M. (2007). Global perspectives on teacher learning: Improving policy and practice. Paris: UNESCO International Institute for Educational Planning.

Tsui, A. B. M. (2003). Understanding expertise in teaching. New York: Cambridge University Press.

UshaRani, P. M. (2012). Self-monitoring - A strategy for teacher development. MAJL, 4(1), Winter, 36-42. Retrieved May 13, 2013, from http://www.mjal.org/Journal/3.Self-Monitoring.pdf

\section{Notes}

Note 1. The detailed information about the development of the MPC Model was in another academic paper written by the same authors.

\section{Copyrights}

Copyright for this article is retained by the author(s), with first publication rights granted to the journal.

This is an open-access article distributed under the terms and conditions of the Creative Commons Attribution license (http://creativecommons.org/licenses/by/3.0/). 